\title{
Critical success factors of ERP implementation in SMEs
}

\author{
Talluri Sai Kiran $^{a^{*}}$ and A Vasudeva Reddy ${ }^{b}$
}

${ }^{a}$ Research Scholar Koneru Lakshmaiah Education Foundation, Green Fields, Vaddeswaram, Guntur, Andhra Pradesh, India-522502, India ${ }^{b}$ Assistant Professor, Koneru Lakshmaiah Education Foundation, Green Fields, Vaddeswaram, Guntur, Andhra Pradesh, India-522502, India

\section{H R O N I C L E}

Article history:

Received: May 82019

Received in revised format: June

22019

Accepted: June 92019

Available online:

June 92019

Keywords:

Enterprise Resource Planning

(ERP)

Small and medium enterprises

ERP implementation

Failures

Success factor

Project

\section{A B S T R A C T}

\begin{abstract}
This paper is aimed at reviewing present state of the art (1998-March 2019) on the impact of Enterprise Resource Planning (ERP) implementation in Small and Medium Enterprises (SMEs). It includes critical success factors and critical failure factors. The technique depends on writing survey for optional information gathering. It characterizes the expressions that are utilized to get explore papers from databases and advanced studies on the ERP implementation in SMEs. It additionally incorporates the consideration and prohibition criteria to improve nature of papers. At that point methodical audit is made on the accessible papers to research the effect of ERP usage in SMEs. Critical factors are identified for success and failure of ERP implementations and actual impact of the same on SMEs (add actual success and failure factors here besides impact). The research found in this paper has limitations in terms of the period of which research papers have been reviewed. An implicit limitation is that it does not consider an empirical study except focusing on the state of the art found in the research area. However, its insights will have potential benefits and the directions for future work. This paper contributes to the research on the impact of ERP implementation on SMEs either positively or negatively. It discovers critical success factors, critical failure factors and impact through secondary data collection method. The insights will help SMEs and stakeholders of SMEs and ERP service providers learn about the reasons for failure or success and take necessary course of action.
\end{abstract}

\section{Introduction}

Small and Medium Enterprises have been striving to get up to date with new technological trends. With respect to various functions associated with different departments, it is understood that they are in need or more comprehensive technology or application like ERP (Zach, 2012; Aremu et al., 2018; Adam et al., 2011; Dlodlo, 2011; Njihia \& Mwirigi, 2014). The following sub sections provide more details.

\subsection{Role of SMES}

SMEs play pivotal role in the economy of a country. Their role is in terms of employment generation, production, equitable distribution of income and contribution to exports. SMEs can be of two kinds basically. The first category is the traditional cottage industries like coir industries, handicrafts

* Corresponding author.

E-mail address: taallurisaiikirran@outlook.com (T.S. Kiran) 
and village industries while the second category is modern SMEs. The former is mostly unorganized and located in semi urban and rural areas. They may not need power operated equipment and need less investment and technology. However, they are crucial in providing employment, at least part time, to large number of populations in a country. Those SMEs can supply essential products that can be consumed by masses and even they can be exported. The latter on the other hand are relatively large of labor and investment. There are small scale sectors that will have specific contributions (Hashi, 2019; Antero, 2015; Tsamantanis \& Kogetsidis, 2006).

The contributions include the leverage of manufacturing sector and country's GDP significantly; adds value to the GDP with contributions in manufacturing. They can contribute in the export promotion through balancing of payment accounts. Unlike large scale organizations that may lead to inequalities in terms of income and wealth, SMEs help in equal distribution of wealth and income. Moreover, small sectors increase in providing opportunities to a large number of entrepreneurs. They can also help in releasing scarce capital for productive use. They can get benefited of lean production and use cost-effective methods for lean production. Resource are optimally utilized in the small units with full capacity and without wastage. Allocation efficiency is also realized. Moreover, the element of risk is low in SMEs and the resource employment can be done in terms of relatively large number of workforce (Hashi, 2019; Branch, 2013; Helo et al., 2004; Tarn et al., 2002).

\subsection{SMEs and Technology Adoption}

Modern SMEs, as mentioned before, exploit technology innovations. Technology adoption is one of the important aspects associated with SMEs. The Indian SMEs have been striving to use technologies for improving productivity (Bhawarkar \& Dhamande, 2012; Mukwasi \& Seymour, 2014; Supramaniam et al., 2014). As far as the usage of new technologies is concerned, SMEs have been on the raise of late. There is a growing trend of this in the contemporary era. The business cases were evolving associated with technological trends (Ruivo, 2013). In the manufacturing especially like pharmaceuticals there has been increased usage of technologies and modern equipment for productivity (Woo, 2007; Markus \& Tanis, 2000; Muscatello et al., 2003; Shahawai et al., 2014).

\subsection{Enterprise Resource Planning in SMEs}

Enterprise Resource Planning (ERP) refers to an integrated and cross -functional system that helps in managing all operations of a company (Al-Mashari, 2002; Singh et al., 2013). ERP system is the backbone for many enterprises across the globe (Alshawi et al., 2004). Of late there has been focused research on the ERP implementations in SMEs. They are found to be highly complex and risky for implementation in enterprises (Aloini et al., 2007). ERP products cover different departments of an organization like Human Resource (HR) (Abduli, 2013), finance, inventory, logistics, accounting and so on. Instead of using separate application for each department, it is better idea to have ERP implementation that drives all functionalities in an integrated fashion (Alshawi et al., 2004; Costa et al., 2016). There are many ERP products of different vendors. Their usage across the world reflects frequency and percentage as shown in Fig. 1 (source: Ehie \& Madsen, 2005). $\mathrm{SAP}$ is found to be very famous with more number of implementations and also frequency of usage.

SMEs have been playing vital role in the economy of countries in the world. They contribute substantially to the national economy and also employment (Alshawi et al., 2004; Seethamraju, 2015). SMEs in India are no exception to this as they have very strategic importance (Bhawarkar \& Dha-

mande, 2012). As there is a growth in business, there is a need for ERP technology that will drive home productivity and efficiency in operations. There have been customizations in ERP implementations to meet the size and scales of operations in different organizations (Baker \& Yousof, 2017; Koh et al., 2006). This is an important reason which makes ERP implementation in SMEs is possible. Moreover, ERP implementations optimize overall performance of organizations (Ash \& Burn, 2003). ERP systems help in business continuity with data and application availability, scalability 
and reliability. This will enable enterprises to be truly competitive in business (Bajgoric \& Moon, 2009; Yusuf et al., 2004).

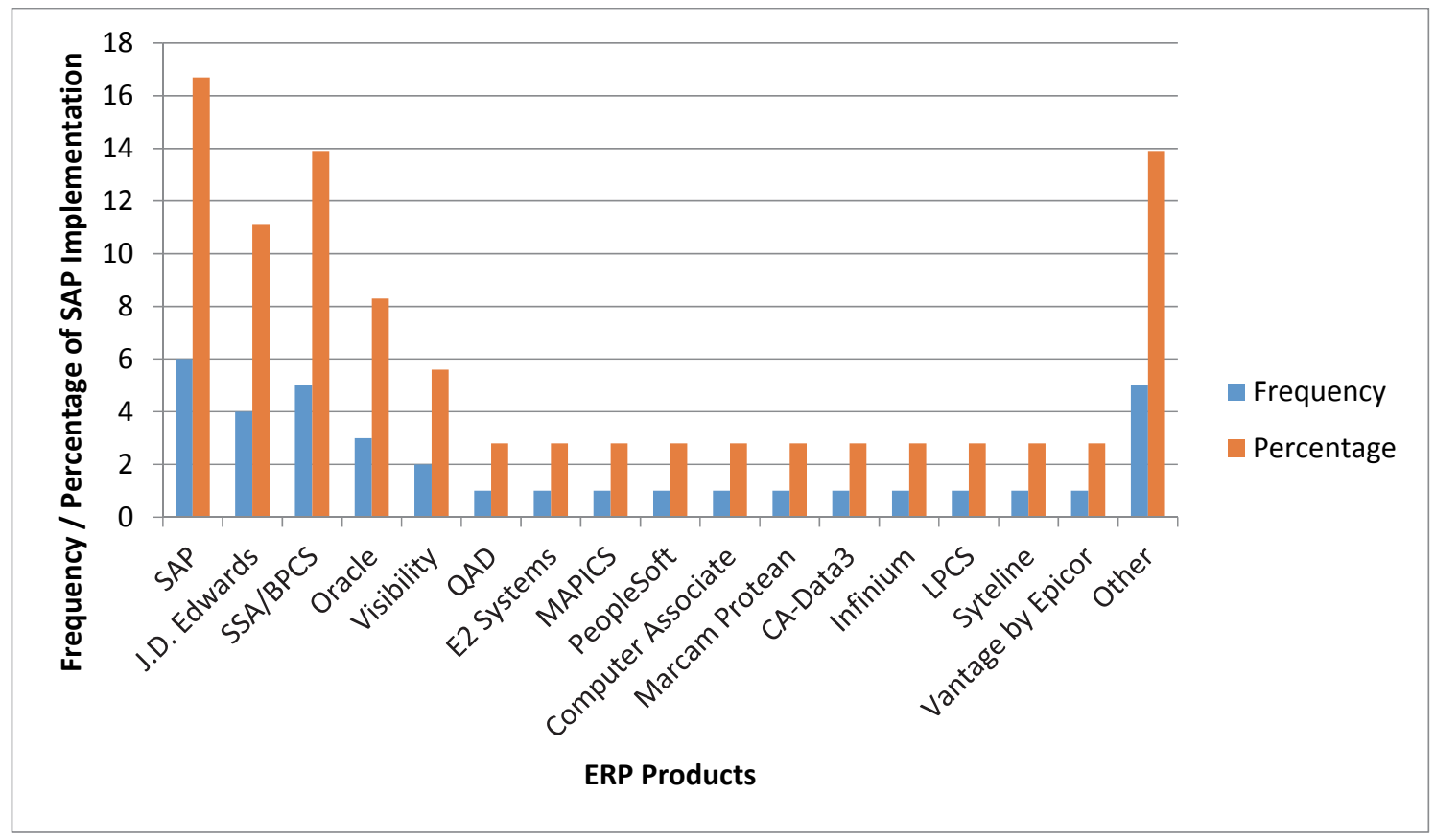

Fig. 1. ERP products and their usage

In essence, putting an enterprise into an enterprise system has many implications (Davenport, 1998). Alternative packages to ERP systems are identified by Elbertsen et al. (2006). ERP adoption is to be carried out systematically to reduce risks associated with failures (Hallikainen et al., 2006, 2009). There are critical issues associated with ERP implementation (Ehie \& Madsen, 2005; Chang et al., 2012). There are many success factors in ERP implementations (Chung et al., 2008; Saini et al., 2013). At the same time, it is understood that there are failure factors too found in the literature. Besides there are certain impacts of ERP implementations in SMEs that are crucial for making well informed decisions (Buleje, 2014; Patil, 2018).

This paper is aimed at investigating success and failure factors of ERP implementation in SMEs besides the impact of the ERP on SMEs. The research is carried out based on the literature on the study considered. The remainder of the paper is structured as follows. Section 2 provides research methodology followed in this paper. Section 3 presents risks associated with ERP implementation. Section 4 covers success factors of ERP implementation. Section 5 discusses the failure factors of ERP implementation. Section 6 covers the impact of ERP on SMEs in nutshell and section 7 concludes the paper.

\section{Methodology}

The research methodology is based on the review of literature on the impact of ERP implementation in SMEs. In other words, it is based on the electronic articles collected from digital libraries and other Internet sources (Basu et al., 2012). Prior to collecting literature on the research area, certain search phrases are identified for faster procurement of papers. The phrases include "ERP dynamics in SMEs", "ERP implementation in SMEs", "ERP success and failure in SMEs" and "SMEs growth and issues with ERP implementations". These search phrases are used in general search engine like Google and search features provided by digital libraries from reputed publishers like IEEE, Google Scholar, Elsevier, Springer and Scopus. After collecting articles needed for the research, they are subjected to pruning with inclusion and exclusion criteria. Inclusion and exclusion criteria include that the research paper is published in a reputed journal, it is highly relevant to the current research topic, it is in the given range of publication years (2998-2019) and there should be take away content 
in the paper. The articles are grouped into categories based on different factors like success factors, failure factors, implementation challenges, impact and other.

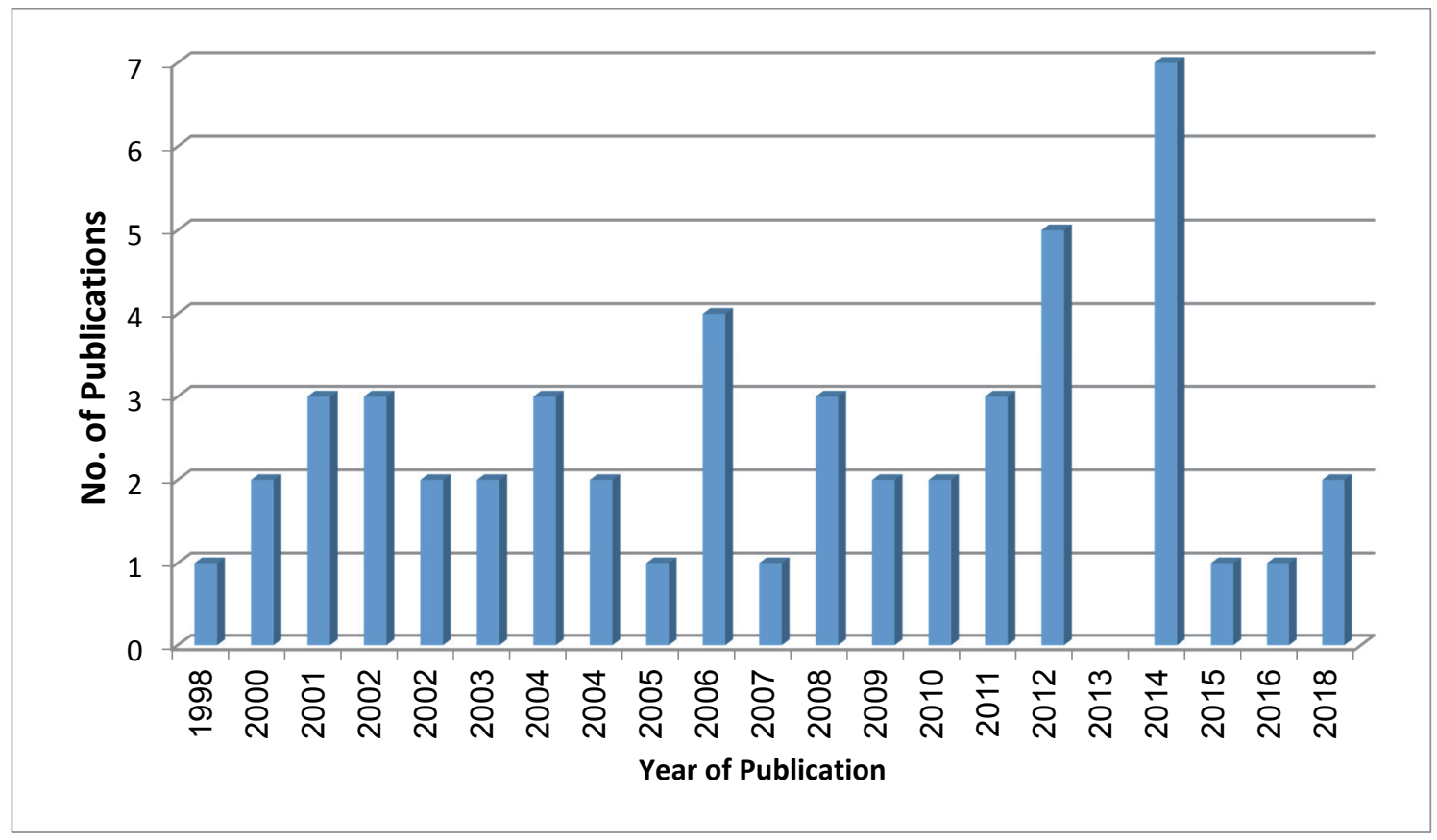

Fig. 2. The summary of articles used for the secondary research

As presented in Fig. 2, it is evident that the longitudinal study considered is from 1998 to 2018. The number of publications are presented after following inclusion and exclusion criteria as part of the methodology provided in this section. The final resultant research papers are used for the study. The following sections provide insights on the findings of the research.

\section{Risk management in ERP implementation for first time}

With respect to SMEs, unfortunately, there are implementation difficulties in ERP implementations. Especially, when ERP is used for the first time, there are issues that affect organization. The contemporary era and integrated e-Business marketplaces emphasize the need for customer centric approaches to have competitive advantages. This has its impact on SMEs to be tempted to go for ERP implementations. Of course, the companies go for this to enhance their business communication systems across the departments and integrate IT infrastructure with ERP system to leverage business processes and ensure organizational growth (Aloini et al., 2007; Helo et al., 2008). When companies do have strong partnership with chain of related businesses, the ERP kind of system can have out of the box solution to enhance business prospects. Supply Chain Management (SCM) and ERP systems are often used to improve performance of organizations. The last decade witnessed thousands of firms across the globe to have ERP implementations that have unified software modules for all kinds of operations (Aloini et al., 2007). Efficient and effective management of resources such as humans, finance, materials and so on is made possible with ERP implementations. ERP systems help SMEs to go for an automated and integrated cross-functional solution that takes care of project management (Tasevska et al., 2014), finance, distribution, procurement, inventory control and other operations (Aloini et al., 2007; Huang et al., 2004; Scott \& Kaindl, 2000). 


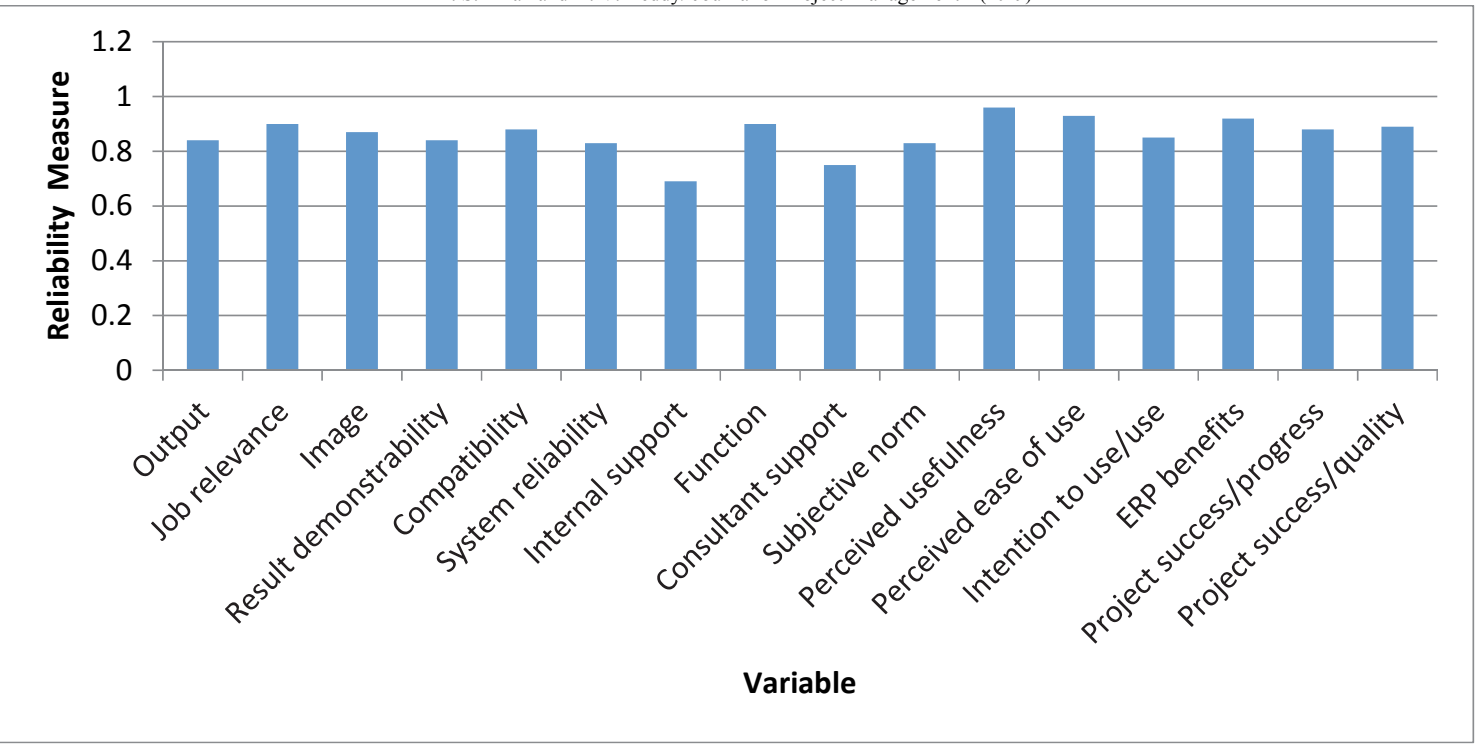

Fig. 3. Reliability measure associated ERP implementations against different variables

As shown in Fig. 3 (source: Aloini et al., 2007) there are many variables with reliability measure. This can provide important insight related to different variables. These are all can be studied in terms of risks. One of the reasons for the failure of ERP implementations is the lack of understanding to managers who are involved in the implementation procedures. Moreover, many project managers in the real-world look risk management procedures as something that is extra and expensive. There are many instances where project managers expunged risk management processes when there is indication of slip in project schedule. In the past, there were many efforts to make successful implementation of ERP (introduction). However, they could not provide expected results. The risk of failure needs to be understood from the standpoint of sheer need for ERP, innovation and past failure experiences if any. In the recent past, many processes came into existence for effective management of risks associated with ERP applications. They include Risk Diagnosing Methodology (RDM), Standards Australia 1999, SAFE Methodology and PMI 2001. These are all iterative processes for risk management. They include different phases like analysing context, identification of risk, analysing risk, evaluation of risk, treating risk, monitoring, reviewing, communication and consulting (Aloini et al., 2007). It is observed that SMEs inadequately manage their risks that lead to failure of systems (Smit and Watkins, 2012). With regard to the discussion above, it is to be kept in mind that ERP implementations are interdisciplinary and cause inter-dependency across processes and software modules. There are critical factors such as management and technological that could be both sociological and psychological. Risk management processes need to consider business, organization, operations, financial matters, market and technology to have appropriate risk management strategy (Aloini et al., 2007; Khaleel et al., 2011). Risks associated with ERP implementations can be categorized into three such as ERP customer company, ERP software provider and ERP system (Iskanius, 2009).

There are many risk factors affecting ERP implementations. Some risks lead to process failure while other risks lead to expectation failure. Some other risks lead to correspondence failure (Aloini et al., 2007). Risk factors include inadequate selection, project team is poor, top management involvement is less, communication system is not effective, user involvement is less, training is inadequate, complex architecture and more number of implementation modules, BPR is inadequate, management decisions are not good, project management techniques are not effective, change management is not adequate, legacy infrastructure management is poor, consulting services are not up to the mark, leadership is poor, inadequate IT infrastructure, IT supplier issues, lack of strategic thinking and planning and ineffective financial management. These risks have several effects such as crossing limits of budget, crossing limits of time, project is stopped, business performance is poor, system 
reliability and stability is poor, processes do not fit, user friendliness issue, low degree of integration, low strategic goals and bad financial performance (Aloini et al., 2007; Themistocleous \& Irani, 2001).

\section{Success parameters of ERP implementation}

There are key parameters that can influence success or failure of ERP implementations in SMEs (Saini et al., 2013; Subba Rao, 2000). Such parameters are provided below.

\subsection{Completion of Project in Given Budget}

This parameter is very crucial as budget overrun causes potential risk to organisations that go for ERP implementations. Therefore, it is the core aspect that needs to be considered as it can cause pressure to the implementation team. According to the study made by Panorama Consulting Group (2010), a survey is conducted with 1600 organisations involved in four years and found that more than half of the enterprises witnessed spending of money beyond budget. The same study revealed that only 8.6 percent of ERP implementations in SMEs could complete in given budget.

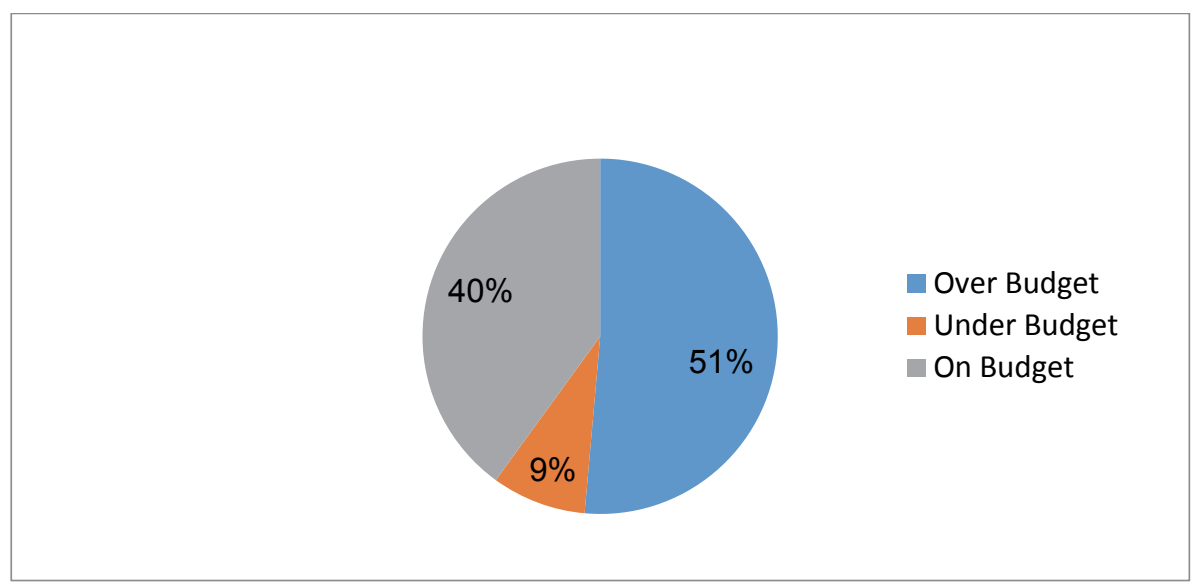

Fig. 4. Statistics on budget in ERP implementations in SMEs (source: Saini et al., 2013)

Having understood the importance of completing projects in given budget, there is another parameter that is also crucial for success of ERP project implementations. It is discussed below.

\subsection{Project Completion in Stipulated Time Frame}

When ERP implementation is not done in stipulated time, it also causes financial issues to the organization. Moreover, it delays performance of organizations and returns of ERP implementation. It also increases the break-even time which needs to be crossed to gain benefits of the software package. As per Panorama Consulting (2010) every 1 organization out of 3 exceeded time budget in ERP implementations. Therefore, project completion time has its influence on the success or failure of the implementation. 


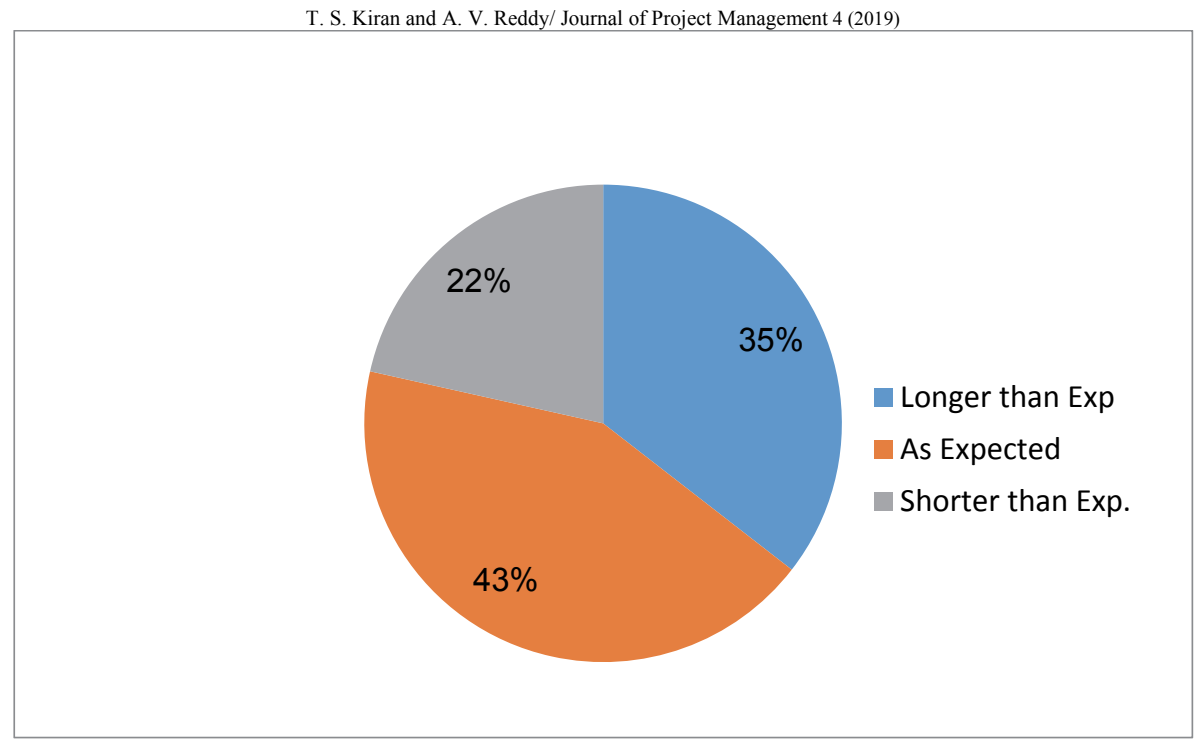

Fig. 5. Trends in time taken for ERP implementations in SMEs (source: Saini et al., 2013)

Fig. 5 shows the project completion time dynamics in ERP implementations. Around $43 \%$ implementations are made on time.

\subsection{Realization of Huge Business Benefits}

When ERP is implemented in any SME, it is understood that the organization wished to have quantum leap in business benefits. When ERP software package is used in the organisation and improve business performance in various aspects, it can lead to realization of business benefits. The promises made in sales pitches can be realized when ERP is implemented in time correctly. Thus it can lead to high volumes of business benefits.

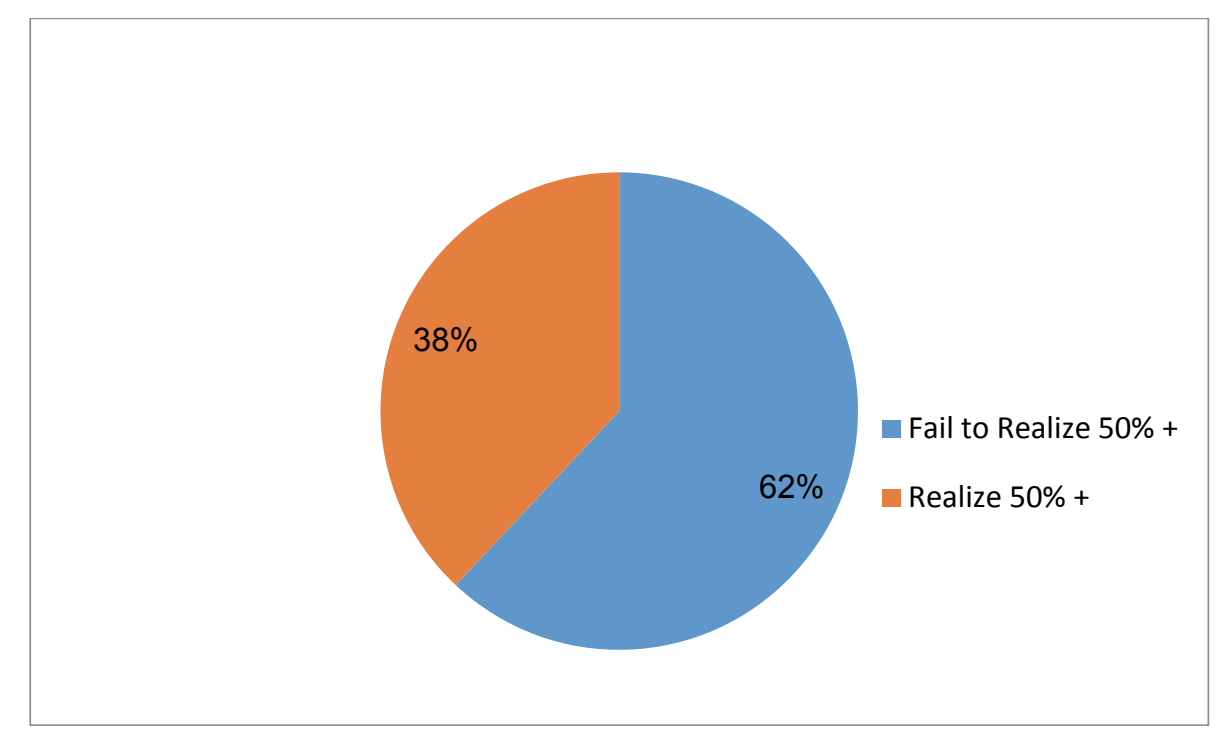

Fig. 6. Trends in realizing huge business benefits

As shown in Fig. 6, it is understood from the study of Panorama Consulting (2010) that nearly 2 out of 3 implementations where not able to have huge business benefits. It shows the severity of issues involved in the ERP implementations. Therefore, huge business benefit is an important parameter to know success of failure of ERP implementation. 


\section{Success factors of ERP implementation}

This section provides different factors that lead to successful ERP implementations in SMEs. From the literature it is understood that there are many factors that can be categorized into people factors, technological factors and organizational factors.

\subsection{Organisational Factors}

ERP implementation needs strong commitment from organization and have strong change management program in presence of people with diversified culture in the organization. When there is organizational commitment, it leads to positive influence on the implementation process. There will be effective management of structural and cultural changes at organization level and workforce level (Rosario, 2000). It is also found in the failure cases that when there is budget overrun, management cut the costs involved in future trainings. This will impact on the implementation and may lead to failure. When proper training is not provided to the users, it is bound to failure. Failure affects many departments and sub-businesses of an organization. Therefore, it is essential to involve end-users while planning design and implementation of ERP system. Smooth transition is possible with effective change management procedures (Holland \& Light, 1999).

\subsection{Top Management Support}

Leadership is provided by top management which is crucial for the success of ERP implementation. Resource allocation and priority to ERP implementation project need support from top level management. Senior management can envisage issues if any and take necessary steps proactively (Sheuet et al., 2004).

\subsection{BPR with Minimum Customization}

ERP systems have many software modules. Accordingly, organizations need to align their business processes to exploit software modules with industry best practices. Thus there will be minimum customization is sufficient. If there is more customization, it may lead to failures in future upgrades from time to time. Therefore, large scale customization in ERP is not recommended. The rationale behind this is that customization of ERP system may render it handicapped (Rosario, 2000). Company's vision and plan should consider full utilization of ERP software. There needs to quantifiable goals and planning needs to be there with risk management procedures in place. Benchmarking practices are to be used in order to have benefits of ERP implementation (Al-Mudimigh et al., 2001). In the process project management and its identification of milestones and critical paths to success is very important. There needs to be very active monitoring of status of project implementation and milestones need to be monitored from time to time and progress has to be assessed (Somers \& Nelson, 2001).

\subsection{Communication}

Communication needs to be effective to disclose progress from time to time to all stakeholders. Timeline and implementation strategy needs to be explicit. Many researchers opined that a phases approach to implementation of ERP is one of the success factors. ERP implementation is made either centralized or decentralized. This decision is also crucial. Based on this decision cost will be influenced. There are unforeseen costs associated with ERP implementations. Therefore, budget needs to be flexible and should not have assumptions and speculations (Al-Mudimigh et al., 2001).

\subsection{ERP Selection}

There are many ERP packages from different vendors. Selection of ERP package is crucial. The ERP software that aligns well to the processes of organization needs to be selected. Selecting consultants and maintaining relationship with them is to be given importance. An external and expert 
consultant is a necessity for successful ERP implementations. The consultant needs to provide sufficient Knowledge Transfer (KT) to the organization to reduce reliance and enhance probability of success (Motwani et al., 2002). Apart from the above, according to Chung et al. (2008), ERP success factors include planning, training, top management support, software selection process, participation, consulting capabilities and consulting support. ERP implementation success also depends on cost, time, performance and benefits (Hong \& Kim, 2002). ERP implementation challenges include inadequate change management, lack of commitment from top management, more customizations, misalignment, lack of sufficient training and lack of understanding of business needs (Momoh et al., 2010). There are 11 factors for successful implementation of ERP. They include teamwork, support from top management, business plan and vision of organisation, effective communication, project management, project champion, usage of legacy systems, change management, BPR, development and troubleshooting, monitoring and evaluation (Nah et al., 2001). According to Seng Woo (2007), success factors include top management, project management, process change, education and training and communication. The factors affecting success in ERP implementation in SME include characteristic of SME, management and its knowledge, products and services, vision and cooperation, resources and finance (Philip, 2010). According to Leyh (2014) critical success factors include ERP system configuration, ERP system tests, organizational fitness for ERP, project management, support from top management and user training.

\section{Failure factors of ERP implementation}

ERP implementation in SMEs is a challenging task. It is challenging as it involves people to deal with before and after implementation. The SME which needs ERP implementation has to take care of effective change management steps at every phase of it. Very good communication, management and training are essential. Many factors may influence failure of ERP implementation. The factors may be many associated with internal staff adequacy, training and change management. There are specific factors that are identified for failure of ERP implementations. They include employee resistance, lack of commitment from top level management, inadequate training and so on. More details are provided here.

Employee Resistance is an important factor as any project fails if personnel are not educated about their perceived benefits. Proper communication, training and involvement of employees is essential. The management also needs to provide job security to employees as the employees will have misconceptions and try to resist or sabotage the efforts of ERP implementation. Lack of commitment from top level management is another factor for failure. The rationale behind this is that without full support from management, the ERP implementation results in many issues. Clearing employee doubts, assuring job security and explaining benefits of ERP system can be done by management effectively. Inadequate training and education also causes failure of ERP implementation. As people are from diversified culture, proper training and education can help them to understand the need for implementation and usage of it after implementation. Different people need different level of training and managers need to have such programs to ensure knowledge transfer as one size does not fit for all. However, everyone needs to have ERP basics, need for automation and the processes involved in it besides involving in change management.

When employees are not fully aware of the new system, they hesitate to use it or they cannot use it optimally. This can lead to failure of the ERP system as the users are not trained well. Another factor is inadequate requirements definition. When requirements are very clearly stated, the implementation team will do it accordingly. Best suited modules in ERP implementation are implemented and training only if requirements are crystal clear. Since ERP system is very complex, inadequate resources is another factor for failure. The implementation is time taking, lengthy and incurs much cost to organization. Often the expected budgets may not be sufficient and there might be hidden and unexpected costs. This has to be kept in mind when budget is allocated and resources are to be planned. Costs, budgets, manpower needs and infrastructure are to be estimated correctly besides having contingency plans to ensure success of ERP implementation. 
Software packages and business processes incompatibility is another cause of failure. There is poor fit between what organization needs and what is being implemented. When the processes in the organization are very strong and there is no optimal package in ERP, then it is indispensable to have customization. However, customization is often error-prone and costly affair. Therefore, it is important to choose correct ERP package from right vendor. Unrealistic expectations with respect to ROI is yet another factor for failure of ERP. Though ERP system improves productivity dramatically, it is required to have realistic expectations on ROI. Miracles cannot be expected from ERP unless the company has its projected growth and customer prospects. When employees and manager know the benefits and scope, they can avoid over expectations. Unfulfilled expectations cause dissatisfaction.

ERP package selection is poor is another factor for failure. When the best suitable package is not selected, it will cause many implementation and customization problems and eventually lead to failure. Choosing not suitable package and choosing a package that needs very high level of customization lead to failure of ERP implementation in SMEs. Therefore, it is essential to ensure that there is best fit between organization processes and the ERP package. Such ERP software need to fulfil the basic needs of an organization. As mentioned above, extensive customization, leads to failure of the system. When there is over-customization, it adds more cost and time and will continue causing issues in future versions. Such system finally makes it increasingly costly and difficult.

Change management is one of the most influencing factors. If there is no adequate procedure in place for change management, it leads to failure of ERP implementation. When change management is not done with standard procedures, it will cause employees to suspect and behave against the implementation of ERP. With respect to heavy customization also change management becomes very complex in future. That will be a problem to organization as it results in difficulties to deal with newer versions of ERP software in future. The ERP implementation needs to support evolving business needs. The rationale behind this is that, there might be changes to be incorporated in future. Business processes may be subjected to change. Such processes are divided into three categories namely strategic planning, management control and controlling operations. As organizations need to re-align their business goals, processes and changes in the market environment. It is found in the literature that many ERP modules re not flexible to the changing and evolving business processes. An ERP system that works well today may need major overhaul in future.

\section{Technical challenges in ERP implementation}

There are many possible technical challenges identified in the literature. The challenges include difficulty in customization, functional complexity in ERP software, application management complexity involved, issues with lack of support from vendors, multi-vendor complexity related to software, hardware and consultants, integrating with legacy systems, security concerns, insufficient IT infrastructure and problems associated with interconnecting functional systems (Kamhawi, 2008).

\section{Conclusions and future scope}

ERP implementation in SMEs have been found appropriate when the SMEs have compatible IT infrastructure and information systems to exploit. Besides it is essential to follow industry best practices. ERP solutions are found to be more useful when full range of its services are used across organization. There has been increase in the usage of ERP in SMEs. However, it is understood from the literature that most of the ERP implementations are not successful. The success percentage is relatively less. This paper has investigated through secondary research and provided insights on success factors, failure factors and impact of ERP implementations. Success factors of ERP implementations include organizational commitment, full support from top level management, BPR with minimum customization, effective communication procedures, suitable ERP package selection and adequate training and change management. ERP failure factors include employee resistance, lack 
of inadequate commitment from top level management, inadequate training and education, inadequate requirements definition, inadequate resources, incompatibility between organization business processes and ERP software, unrealistic expectations on ROI, poor selection of ERP packages, heavy customizations and change management inefficiency. The impact of the ERP implementation in SMEs is found positively and negatively as well. Again it is attributed to success and failure factors. Successful implementations have affected SMEs to grow economically and in terms of productivity as well. There is some period that needs for stabilization. However, the overall impact is impressive when implementation is made successfully and the company used it effectively.

\section{References}

Abduli, S. (2013). Effective human resource management in small and medium size enterprises in the republic of Macedonia. International Journal of Academic Research in Economics and Management Sciences, 2(2), 169-183.

Adam, R., Kotze, P., \& Van der Merwe, A. (2011). Acceptance of enterprise resource planning systems by small manufacturing Enterprises. 1-10.

Al-Mudimigh, A., Zairi, M., \& Al-Mashari, M. (2001). ERP software implementation: an integrative framework. European Journal of Information Systems, 10(4), 216-226.

Aremu, A. Y., Shahzad, A., \& Hassan, S. (2018). Determinants of Enterprise Resource Planning adoption on organizations' performance among medium enterprises. LogForum, $14 . .14$ (2), 245255.

Al-Mashari, M. (2003). Enterprise resource planning (ERP) systems: a research agenda. Industrial Management \& Data Systems, 103(1), 22-27.

Aloini, D., Dulmin, R., \& Mininno, V. (2007). Risk management in ERP project introduction: Review of the literature. Information \& Management, 44(6), 547-567.

Alshawi, S., Themistocleous, M., \& Almadani, R. (2004). Integrating diverse ERP systems: a case study. Journal of Enterprise Information Management, 17(6), 454-462.

Antero, M. C. (2015). A Multi-case Analysis of the Development of Enterprise Resource Planning Systems (ERP) Business Practices. Morten Friis-Olivarius The Associative Nature of Creativity.

Ash, C. G., \& Burn, J. M. (2003). A strategic framework for the management of ERP enabled ebusiness change. European journal of operational research, 146(2), 374-387.

Bajgoric, N., \& Moon, Y. B. (2009). Enhancing systems integration by incorporating business continuity drivers. Industrial Management \& Data Systems, 109(1), 74-97.

Baker, M.B., \& Yousof, Z. (2017). Factors Influencing Knowledge Sharing in Enterprise Resource Planning System usage in Small and Medium Enterprises. Journal of Theoretical and Applied Information Technology, 95(8), 1-10.

Basu, R., Upadhyay, P., Das, M. C., \& Dan, P. K. (2012). An approach to identify issues affecting ERP implementation in Indian SMEs. Journal of Industrial Engineering and Management (JIEM), 5(1), 133-154.

Bhawarkar, R.M., \& Dhamande, L.P. (2012). Exploring Enterprise Resource Planning (ERP) System Outcomes in Indian Small and Medium Enterprises (SME's). International Journal of Engineering Research \& Technology, 1(4), 1-8.

Branch, J. (2013). The role of enterprise resource planning (ERP) for small and medium enterprises (SMEs). Research Journal of Applied Sciences, Engineering and Technology, 5(7), 2317-2320.

Buleje, M. (2014). The Impact of Enterprise Resource Planning Systems on Small and Medium Enterprises.

Chang, S. I., Yen, D. C., Ng, C. S. P., \& Chang, W. T. (2012). An analysis of IT/IS outsourcing provider selection for small-and medium-sized enterprises in Taiwan. Information \& Management, 49(5), 199-209.

Leyh, C. (2014, September). Critical success factors for ERP projects in small and medium-sized enterprises-The perspective of selected German SMEs. In 2014 Federated Conference on Computer Science and Information Systems(pp. 1181-1190). IEEE. 
Chung, B. Y., Skibniewski, M. J., Lucas Jr, H. C., \& Kwak, Y. H. (2008). Analyzing enterprise resource planning system implementation success factors in the engineering-construction industry. Journal of Computing in Civil Engineering, 22(6), 373-382

Costa, C. J., Ferreira, E., Bento, F., \& Aparicio, M. (2016). Enterprise resource planning adoption and satisfaction determinants. Computers in Human Behavior, 63, 659-671.

Davenport, T. H. (1998). Putting the enterprise into the enterprise system. Harvard business review, 76(4), 121-31.

Dlodlo, J. B. (2011). Enterprise resource planning in manufacturing SMEs in the Vaal Triangle (Doctoral dissertation, North-West University).

Fakeeh, K. A., Qayyum, J., \& Albarakati, A. J. (2014). Enterprise resource planning on cloud for small and medium sized business. International Journal of Computer Science and Mobile Computing, 3(10), 571-583.

Ehie, I. C., \& Madsen, M. (2005). Identifying critical issues in enterprise resource planning (ERP) implementation. Computers in industry, 56(6), 545-557.

Elbertsen, L., Benders, J., \& Nijssen, E. (2006). ERP use: exclusive or complemented?. Industrial Management \& Data Systems, 106(6), 811-824.

Hallikainen, P., Kimpimaki, H., \& Kivijarvi, H. (2006, January). Supporting the module sequencing decision in the ERP implementation process. In HAWAII INTERNATIONAL CONFERENCE ON SYSTEM SCIENCES (Vol. 39, p. 181). IEEE.

Hallikainen, P., Kivijärvi, H., \& Tuominen, M. (2009). Supporting the module sequencing decision in the ERP implementation process - An application of the ANP method. International Journal of Production Economics, 119(2), 259-270.

Hashi, S. (2019). Role of Small and Medium Enterprises In Economic Development. Retrieved From: https://www.linkedin.com/pulse/role-small-medium-enterprises-economic-developmentsaeed-hashi.

Helo, P., Anussornnitisarn, P., \& Phusavat, K. (2008). Expectation and reality in ERP implementation: consultant and solution provider perspective. Industrial Management \& Data Systems, 108(8), 1045-1059.

Hong, K. K., \& Kim, Y. G. (2002). The critical success factors for ERP implementation: an organizational fit perspective. Information \& management, 40(1), 25-40.

Huang, M. H., Wang, J. C., Yu, S., \& Chiu, C. C. (2004). Value-added ERP information into information goods: an economic analysis. Industrial Management \& Data Systems, 104(8), 689-697.

Njihia, E., \& Mwirigi, F. M. (2014). The effects of enterprise resource planning systems on firm's performance: A survey of commercial banks in Kenya. International journal of business and commerce, 3(8), 120-129.

Philip, M. (2011). Factors affecting business success of small \& medium enterprises (SMEs). Amity Global Business Review, 6(1), 118-136.

Patil, S.Y. (2018). Enterprise resources planning in small and medium-sized enterprises: An overview. A National Research Journal, 2(2), 1-8.

Iskanius, P. (2009). Risk Management in ERP Project in the Context of SMEs. Engineering Letters, 17(4).

Kamhawi, E. M. (2008). Enterprise resource-planning systems adoption in Bahrain: motives, benefits, and barriers. Journal of Enterprise Information Management, 21(3), 310-334.

Khaleel, Y., Sulaiman, R., Ali, N. M., \& Baharuddin, M. S. (2011). Analysis of enterprise resource planning system (ERP) in small and medium enterprises (SME) of Malaysian manufacturing sectors: current status and practices. Asia-Pacific Journal of Information Technology and Multimedia, 10(1).

Koh, S. L., Simpson, M., Padmore, J., Dimitriadis, N., \& Misopoulos, F. (2006). An exploratory study of enterprise resource planning adoption in Greek companies. Industrial Management \& Data Systems, 106(7), 1033-1059.

Markus, M. L., \& Tanis, C. (2000). The enterprise systems experience-from adoption to success. Framing the domains of IT research: Glimpsing the future through the past, 173(2000), 207-173. 
Momoh, A., Roy, R., \& Shehab, E. (2010). Challenges in enterprise resource planning implementation: state-of-the-art. Business Process Management Journal, 16(4), 537-565.

Motwani, J., Mirchandani, D., Madan, M., \& Gunasekaran, A. (2002). Successful implementation of ERP projects: evidence from two case studies. International Journal of Production Economics, 75(1-2), 83-96.

Mukwasi, C. M., \& Seymour, L. F. (2014). The growing trend of small to medium-sized enterprises adopting enterprise resource planning systems: an analysis of business cases in Zimbabwe and South Africa. Journal of Emerging Trends in Economics and Management Sciences, 5(7), 138145.

Muscatello, J. R., Small, M. H., \& Chen, I. J. (2003). Implementing enterprise resource planning (ERP) systems in small and midsize manufacturing firms. International Journal of Operations \& Production Management, 23(8), 850-871.

Nah, F. F. H., Lau, J. L. S., \& Kuang, J. (2001). Critical factors for successful implementation of enterprise systems. Business process management journal, 7(3), 285-296.

Rosario, J.G. (2000). On the leading edge: critical success factors in ERP implementation projects. BusinessWorld, Philippines.

Ruivo, P. M. F. (2013). A technology diffusion perspective of Enterprise Resource Planning across European Small and Medium Enterprises: from determinants to Use to Value, 1-159.

Saini, S., Nigam, S., \& Misra, S. C. (2013). Identifying success factors for implementation of ERP at Indian SMEs: a comparative study with Indian large organizations and the global trend. Journal of Modelling in Management, 8(1), 103-122.

Subba Rao, S. (2000). Enterprise resource planning: business needs and technologies. Industrial Management \& Data Systems, 100(2), 81-88.

Scott, J. E., \& Kaindl, L. (2000). Enhancing functionality in an enterprise software package. Information \& Management, 37(3), 111-122.

Seethamraju, R. (2015). Adoption of Software as a Service (SaaS) Enterprise Resource Planning (ERP) systems in Small and Medium Sized Enterprises (SMEs). Information Systems Frontiers, $17(3), 475-492$.

Seng Woo, H. (2007). Critical success factors for implementing ERP: the case of a Chinese electronics manufacturer. Journal of manufacturing technology management, 18(4), 431-442.

Singh, G., Manna, M. S., \& Bhasin, G. S. (2013). A Study of Impact of ERP and Cloud Computing In Business Enterprises. LAP LAMBERT Academic Publishing.

Smit, Y., \& Watkins, J. A. (2012). A literature review of small and medium enterprises (SME) risk management practices in South Africa. African journal of business management, 6(21), 6324.

Supramaniam, M., Abdullah, A., \& Ponnan, R. (2014). Cost analysis on ERP system implementation amongst Malaysian SMEs. International Journal of Trade, Economics and Finance, 5(1), 72.

Shahawai, S. S., Hashim, K. F., \& Idrus, R. (2014). Enterprise Resource Planning Adoption among Small Medium Enterprises (SME) in Malaysia.

Tarn, J. M., Yen, D. C., \& Beaumont, M. (2002). Exploring the rationales for ERP and SCM integration. Industrial Management \& Data Systems, 102(1), 26-34.

Tasevska, F., Damij, T., \& Damij, N. (2014). Project planning practices based on enterprise resource planning systems in Small and Medium Enterprises - A Case Study From the Republic of Macedonia. International Journal of Project Management, 32(3), 529-539.

Themistocleous, M., \& Irani, Z. (2001). Benchmarking the benefits and barriers of application integration. Benchmarking: An International Journal, 8(4), 317-331.

Tsamantanis, V., \& Kogetsidis, H. (2006). Implementation of enterprise resource planning systems in the Cypriot brewing industry. British Food Journal, 108(2), 118-126.

Yusuf, Y., Gunasekaran, A., \& Abthorpe, M. S. (2004). Enterprise information systems project implementation:: A case study of ERP in Rolls-Royce. International journal of production economics, 87(3), 251-266.

Zach, A. (2012). ERP System Implementation in Small and Medium-Sized Enterprises. Faculty of Economics and Social Sciences, 1-197. 
(C) 2018 by the authors; licensee Growing Science, Canada. This is an open access article distributed under the terms and conditions of the Creative Commons Attribution (CC-BY) license (http://creativecommons.org/licenses/by/4.0/). 